\title{
El fascismo: la barbarie moderna (y II)
}

\author{
José Ramón Catalán \\ Departamento de filosofía \\ UCA, San Salvador
}

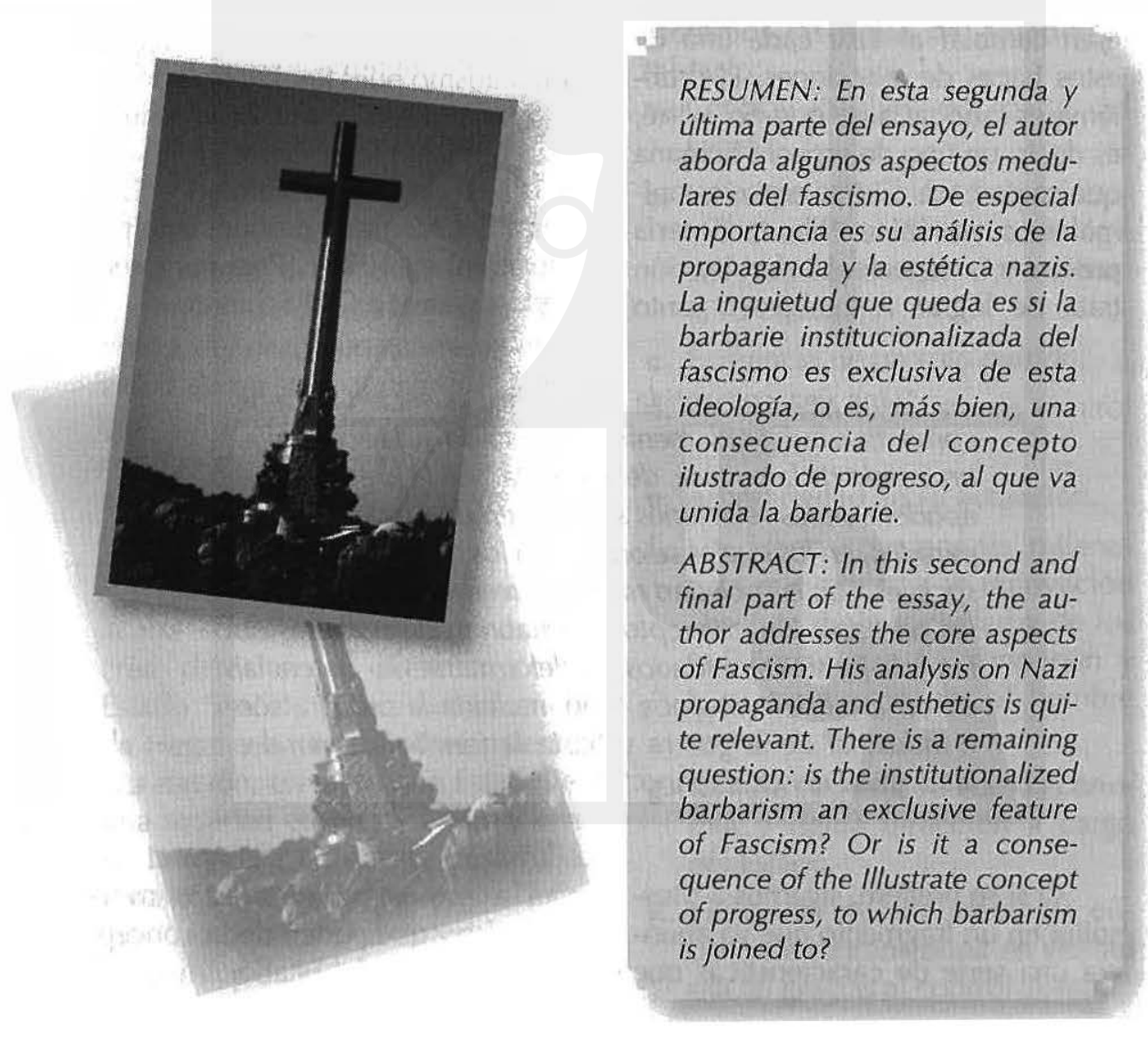


$\mathrm{H}$ annah Arendt concluye que lo que persigue un Estado totalitario no es sólo la transformación del mundo exterior o de la sociedad, sino de la misma naturaleza humana: "La dominación total que aspira a organizar la infinita pluralidad y la diferenciación de los seres humanos como si la humanidad fuese justamente un individuo, sólo es posible si todas y cada una de las personas pudieran ser reducidas a una identidad nunca cambiante de reacciones, de forma tal que se pudieran cambiar al azar cada uno de estos haces de reacciones. El problema es fabricar algo que no existe, es decir, un tipo de especie humana que se parezca a otras especies animales, cuya única "libertad" sería preservar la especie. La dominación trata de lograr este objetivo tanto a través del adoctrinamiento ideológico de las formaciones de elite como a través del terror absoluto en los campos; y las atrocidades para las que son implacablemente empleadas las formaciones de elite se han convertido en realidad, en aplicación práctica del adoctrinamiento ideológico —en terreno de pruebas en el que demostrarse éste- mientras que se supone que el aterrador espectáculo de los mismos campos ha de proporcionar la comprobación teórica de la ideología."

Conozcamos más de cerca el totalitarismo pues las palabras de Arendt son graves: cambiar la naturaleza humana. Jean Pierre Faye sitúa el origen de este vocablo en el Discurso del Augusteo pronunciado por Mussolini en $1925 .^{2}$ Para comprenderlo sigamos a Carl Schmitt:

"Una vez convertida en Estado, la sociedad debe convertirse indefinidamente en un Estado de la economía, un Estado de la cultura, del bienestar, de la previsión. Se apodera de las relaciones sociales en una totalidad. Los partidos, en los cuales se organizan los diversos intereses sociales, son la sociedad misma convertida en Estado de los partidos. Un concepto que habrían descubierto en Francia juristas y soldados, el del armamento potencial de un Estado, lo engloba todo, incluida la preparación e industrial de la guerra y hasta la formación moral e intelectual del ciudadano." 3

O si se prefiere, sigamos a Mussolini en un fragmento que ya anuncia una serie de características que van a presentar todos estos movimientos y que parten de la concepción totalitaria del Estado. 
"No es la nación la que crea el Estado, como en la vieja concepción naturalista, que servía de base a los estudios de los publicistas de los Estados nacionales del siglo XIX. Al contrario, la nación es creada por el Estado, que da al pueblo, consciente de su propia unidad moral, una voluntad y por consiguiente una existencia efectiva. El Estado, en tanto voluntad ética universal, crea derecho." ${ }^{\prime 4}$

De lo dicho, ya podemos sacar una conclusión: la sociedad civil es fagocitada por el Estado con las consecuencias que esto acarrea; la primera será la falta de libertad, tanto en su aspecto negativo como positivo. Analicemos esto siguiendo a Isaiah Berlin. ${ }^{5}$ Comencemos con la libertad negativa: "La libertad política es, simplemente, el espacio en el que un hombre puede actuar sin ser obstaculizado por otros. (...) Libertad en este sentido es estar libre 'de'".

$Y$ ahora, la positiva: "El sentido "positivo" de la palabra libertad se deriva del deseo por parte del individuo de ser su propio amo. Quiero que mi vida y mis decisiones dependan de mí mismo y no de fuerzas exteriores, sean éstas del tipo que sean".

Pero el Estado totalitario no sólo acaba con las libertades, no sólo crea derecho, se presenta como Estado "ético", y aquí la influencia de Hegel en Mussolini ${ }^{6}$ es patente. "La nación, en tanto que Estado, es una realidad ética que existe y vive en la medida en que se desarrolla. Para ella detenerse es morir. El Estado no es sólo una autoridad que gobierna y da forma legal y valor de vida espiritual a las voluntades individuales; es una potencia que hace valer su voluntad en el exterior, haciéndose reconocer y respetar, demostrando con hechos su universalidad en todas las manifestaciones necesarias de su desarrollo."

Llegados a este punto, enumeremos las notas del Estado totalitario:

a. Control absoluto por parte del Estado.

b. Instrumentalización de los conocimientos científicos y tecnológicos para llevar aquel control hasta su extremo.

c. Existencia de un sólo partido.

d. Un sistema terrorista de control policíaco.

e. Arbitrariedad en su actuación.

f. Un fuerte componente milenarista que aspira a la renovación absoluta de la sociedad y de los individuos que la componen y a su sustitución por el hombre nuevo.

g. Control centralizado de la economía y rígida dirección a cargo del Estado.

h. Existencia de una ideología oficial que se transforma en verdad oficial gracias al control absoluto 
de los medios de comunicación.

i. Aparición de un jefe carismático y de una elite protagonista del régimen, que constituyen la cabeza visible $y$ venerada del Estado.

Eslas características, aunque de forma diferente, las compartieron todos los movimientos derechistas ultraviolentos: fascismo, nazismo, nacional-sindicalismo, etc. Por ello, podemos, siguiendo el concepto de "definición" de Aristóteles, género próximo y diferencia específica, considerar el totalitarismo como el género que albergó a todos ellos. Por otra parte, el extremado nacionalismo (la diferencia específica) sería la causa de sus distintas denominaciones: Italia, fascismo; Alemania, nazismo; España, nacional-sindicalismo; etc..

Si observamos con detenimiento dichas características, se apreciará que el enemigo a batir es el individualismo burgués causante de las crisis sociales por las que atravesaban estas sociedades y de la que estos movimientos se consideraban salvadores.

"El totalitarismo es la reacción lógica a un proceso de atomización, a la pérdida de solidaridad orgánica; es la respuesta enloquecida que halla la organización economicista a un individualismo que le fue necesario al principio pero que lleva en sí elementos de anarquía y de disgregación que no son integrables. En resumen, el individualismo burgués de un capitalismo competitivo no es adecuado cuando lo que está en tela de juicio es la racionalización total de la economía y de la existencia. El totalitarismo cree así realizar en torno a un valor dominante una unidad necesaria para la perduración social; sin embargo esta unidad - sería preferible llamarla interdependencia - va a obtenerse por arriba por medio de un órgano centralizador y no a partir de la espontaneidad social"

Es esta idea de unidad de lo disperso, de haz, de manojo, lo que significa "fascis"; de ahí "fascismo", y quizá por ello haya dado nombre como género a los otros movimientos aunque como se ha visto, es simplemente una especie.

Pero hasta el momento sólo nos hemos detenido en el funcionamiento del Estado totalitario de cara al interior $y$ ahora es el momento de verlo de cara al exterior, pues es aquí donde todos ellos muestran una clarísima vocación imperialista. Si el individuo desaparece en el seno del Estado, éste ahora se constituye como un macroindividuo que peleará por su expansión con otros.

El principal ideólogo del fascismo español, Giménez Caballero, así lo veía: 
"Sólo ha existido en el mundo un sistema eficaz para superar ese encono eterno de clases; y es trasla. dar esa lucha social a un plano distinto. Trasladarla del plano nacional al internacional. El pobre $y$ el rico de una nación sólo se ponen de acuerdo cuando ambos se deciden a atacar a otros pueblos o tierras donde pueden existir riquezas o poderío para todos los atacantes. El sentimiento de igualdad social que origina toda lucha de clases sólo se supera llevando esa igualdad en el ataque a otros paises que son desiguales a nosotros. ${ }^{\prime 8}$

Llegados a este punto, ya se puede ver con mayor claridad que un Estado totalitario con vocación imperialista sólo se puede apoyar en una economía planificada imperativamente y en una movilización permanente de las masas. Pues bien, para Renzo de Felice, uno de los más conocidos y reputados analistas del fascismo, es justamente la movilización permanente la que distingue a un régimen fascista de otros como los conservadores $y$ autoritarios. Démosle la palabra.

"Los regímenes conservadores y autoritarios clásicos han tendido siempre a desmovilizar a las masas y a excluirlas de la participación activa de la vida política, ofreciéndoles valores y un modelo social ya experimentados en el pasado, a los que se les atribuye la capacidad de impedir los inconvenientes y los errores de algún paréntesis revolucionario reciente. Por el contrario, el fascismo siempre ha intentado ( $y$ en eso se basa en gran medida su fuerza) crear en las masas la sensación de estar siempre movilizadas, de tener una relación directa con el jefe ( que es tal por ser capaz de ser el intérprete y el traductor en los actos de sus aspiraciones) y de participar y de contribuir no en una mera restauración de un orden social cuyos limites e inadecuación históricos todos comprendian, sino en una revolución en la que gradualmente nacería un nuevo orden social mejor y más justo que el preexistente. En ello se basa el consenso de que disfrutó el fascismo."

Considero fundamentales estas líneas de Renzo de Felice, pues vienen a poner orden en los mapas políticos, ya que hoy por hoy, a cualquier dictadura se la califica como fascista, cuando como dice nuestro autor, más que movilizar a las masas, las paralizan. De ahí que 
sostenga que el fascismo, hablando en general, sea un fenómeno de entreguerras, lo que no quita en ningún momento ni gravedad ni importancia a las crudelísimas y sangrientas dictaduras que, tras la Segunda Guerra Mundial, han padecido muchísimos países.

En esta misma línea se pronuncia Umberto $\mathrm{Eco}^{10}$ :

"Le sucede a la noción de fascismo lo que, según Wittgenstein, le sucede a la noción de juego. Un juego puede o no ser una competición, puede implicar una o varias personas, puede requerir o no una habilidad especial, puede o no exigir sumas de dinero. Los juegos son una serie de actividades diversas que reflejan solamente un cierto aire familiar. (...) El fascismo se ha convertido en un término que se adapta a todo porque incluso si se eliminan de un régimen fascista una o varias notas, siempre será posible reconocerlo como fascista. Así elimínese el imperialismo y obtendremos el régimen de Franco y Salazar."

\section{Líder carismático y dictadura. Élites y antiparlamentarismo}

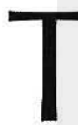

homas Carlyle ${ }^{11}$ sostiene que las revoluciones y demás convulsiones sociales se desarrollan por la ausencia de lo que el denomina "el hombre capaz", de ahí que su aparición traiga la paz. Esta persona es obedecida incondionalmente, pues todos concuerdan que está tocado por la divinidad, que tiene "gracia", carisma, diría Max Weber; así pues, no conoce ninguna limitación, su poder es absoluto. Pero esto, ¿no parece devolvernos al pasado?

En la teoría del derecho divino, siguiendo a John Neville Figgis ${ }^{12}$, encontramos cuatro principios que rezan:
a.-La monarquía -el líder carismático, para nosotros- es una institución de origen divino.

b.- El derecho hereditario es irrevocable. Nosotros hablaríamos de rutinización del carisma.

c.- Los Reyes - los líderes carismáticos- sólo son responsables ante Dios; ante la Historia, también, podemos añadir.

d.-La no resistencia y la obediencia pasiva son prescripciones divinas.

Obviamente, esta teoría del derecho divino de los Reyes debemos enmarcarla en su época e interpretarla como una reivindicación 
del poder real frente al Papa. No obstante, parece resumir muy bien aquellas notas que también definen a un líder carismático.

$\mathrm{Si}$ el período de entreguerras es crítico, como ya ha quedado de manifiesto, es normal entonces la aparición de estos "grandes hombres". Ellos son el brazo ejecutor de una voluntad que transciende to individual y que puede designarse como voluntad de Dios, de la Nación, de la colectividad, de la época. Ante el naufragio de las instituciones, caducas, envilecidas, corruptas e inoperantes, la confianza de las masas se deposita en el "salvador", el "mesías", el "enviado".

Todavía en la España franquista en 1975, leíamos en las monedas : "Francisco Franco, Caudillo de España por la gracia de Dios". Mussolini, es el "Guía". Hitler, ya en 1921 es comparado con el Mesías y cada uno de los soldados cuando muere, "muere caído en la fe de Adolf Hitler". Afirma Rosa Sala ${ }^{13}$ que el culto a su personalidad fue tan elevado que, paradójicamente, se le desligó del nazismo.

Pero aprendamos algo más de los líderes carismáticos siguiendo a Max Weber ${ }^{14}$. Después de definir la dominación como "la probabilidad de encontrar obediencia dentro de un grupo determinado para mandatos específicos o para toda clase de mandatos", pasa revista a los distintos tipos sin perder de vista el soporte de todos ellos: la legitimidad en sus diversas variantes; según sea ésta así será la dominación. Si la racional descansa en la creencia en la legalidad de las ordenaciones estatuidas, y la tradicional, en la santidad de las tradiciones, la carismática lo hace en la entrega extracotidiana a la santidad, heroísmo o ejemplaridad de una persona y a las ordenaciones por ella creadas - reveladas. La primera supone una ordenación impersonal, no así las otras, sin embargo, mientras la tradicional apela a la tradición, por lo tanto a una cosmovisión compartida, la carismática $-y$ esto es importante- aparece allí donde no existen los valores o son compartidos de forma mínima. Recuérdese que el mito llena un vacío. Jean la Couture habla de "líder por destino", aquél que no duda de que ha sido llamado, de ser necesario $y$ legítimo.

Otro aspecto relevante de la dominación carismática es el proceso de comunización, es decir, el cuadro administrativo de los líderes no es ninguna burocracia, $y$ menos que nada una burocracia profesional, sino una extensión - de ahí comunización- del carisma y así aparecen "los hombres de confian$\mathrm{za}^{\prime \prime}$. Y de aquí se derivan dos consecuencias de gran relevancia.

En primer lugar no hay principios jurídicos abstractos ni reglamentos ni árbitros ni sentencias orientadas por precedentes tradicionales; lo decisivo son las creaciones de derecho caso a caso, es decir, que se cae en la arbitrariedad's. 
Y en segundo lugar, lo ya apuntado por Hannah Arendt ${ }^{16}$, la existencia de un Estado dentro de otro, uno reglamentado y otro sin reglamentar, de forma que los cargos "políticos" no tienen presencia en la toma de decisiones. El mejor ejemplo de todo esto lo encontramos en la Conferencia de Bansee el 20 de enero de 1942 en la que se "adoptó" la "solución final". Idea de Goering, fue R. Heydrich - con el apoyo de Eichmann- el encargado de hacer saber a altos cargos "políticos" lo que ya se había decidido hacer con los judios. Así, la reunión fue simplemente informativa, nunca deliberativa.

Pero tampoco conviene olvidar que, según Martínez Arranz,

I.- El carisma no es un dato fijo, hay grados.

2.- Es inherentemente inestable.

3.- En todos los casos, cabe preguntar "para quién, cuándo y en qué grado" es un líder carismático.

Volvamos de nuevo a Lévinas y a su tesis el nazismo como biologismo y pensemos en una metáfora política potente. Si la sociedad, ese macrosujero, es un cuerpo, ¿cuántas cabezas tiene? Tan sólo una. Por tanto la institución política que la representa será la dictadura. ¿No consideramos en un cuerpo miembros más "nobles" que otros? Habrá por tanto una élite. Pero dicho esto, también conviene precisar que ni Hitler ni Mussolini se consideraron dictadores, sino líderes cuyo carisma les fue reconocido por sus respectivas poblaciones sin dudarlo.

\section{¿Dictadura?}

Por lo ya dicho, se comprenderá que estos regímenes no fueron nunca constitucionales, porque como afirma C. Mcllwain"... en todas sus fases sucesivas, el constitucionalismo tiene una esencial cualidad: implica la limitación jurídica del gobierno; es la antítesis del gobierno arbitrario; es lo contrario del gobierno despótico, del gobierno del capricho en vez del derecho. En los tiempos modernos, a esto se ha añadido la expansión de la responsabilidad a través de la consecución de la iniciativa en las materias discrecionales de la política nacional de los representantes del pueblo; pero el rasgo más antiguo, constante y duradero del verdadero constitucionalismo continúa siendo, como lo ha sido desde el comienzo, la limitación del gobierno por el derecho" ${ }^{\prime 17}$.

Pero también, por lo ya dicho, se comprenderá que vertebrar el Estado nazi por medio de una constitución sería una verdadera contradicción, pues justamente la limitación de poderes que apunta McIlwain iría contra la figura del líder carismático, que debe tomar permanentemente decisiones importantes y no debe encontrarse con obstáculos legales.

\section{Élite $y$ antiparlamentarismo}

Según Peter Bachrach ${ }^{i \theta}$,"la defensa moderna del elitismo se basa principalmente en el postulado de que el bien de un pueblo libre $y$ 
de la propia civilización depende de la capacidad de los dotados para conducir a las mayorías que acatan sus dictámenes con vistas al interés general."

Son dos los supuestos en los que se fundamenta la teoría de las élites:

\section{I.- La masa es intrínsecamente in- competente.}

2.- Que es, en el mejor de los casos, materia inerte y moldeable a voluntad; $y$ en el peor, la masa es ingobernable y desenfrenada, con proclividad insaciable a minar la cultura y la libertad.

Para G. Mosca', uno de los principales ideólogos del fascismo italiano, "cuanto más vasta es una comunidad política, tanto menos puede ser la proporción de la minoría gobernante con respecto a la mayoría gobernada, y tanto más difícil le resultará a ésta organizarse para actuar contra aquella".

La teoría elitista no es sino la respuesta a la incapacidad de las instituciones democráticas para dirigir un país. Recuérdese que esta teoría no tiene nada de nueva pues ya la planteó Platón en La república cuando tras la condena y muerte de Sócrates, abogaba por aquellos "filósofos-reyes", únicos capaces de regir los destinos de la polis, por sabios. Lo que en el fondo se pretende es una racionalización de la sociedad basada en la división del trabajo, racionalización que acarreará el fin del parlamentarismo.
Para C. Schmitt ${ }^{20}$, la evolución de la moderna democracia de masas ha convertido la discusión pública en una formalidad vacía. Los partidos políticos se enfrentan guiados por sus ansias de poder, $y$ de este modo los argumentos se transforman en sugestiones persuasivas para ganar el apoyo de la masa dando como resultado la dictadura de la mayoría. Y es que, según Schmitt, el parlamentarismo es propio del liberalismo pero no de una democracia. ¿Cómo podemos entender esto?

Hay que dejar claro que para Schmitt hay dos clases de representación: "vertretung", representación mediante elecciones, $y$ "repräsentation" o representación espiritual.

Si nos detenemos a pensar, todo va encajando. ¿Podemos considerar tanto el régimen nazi como el fascista como verdaderas democracias? La contestación más rápida sería que no, pero ino resuenan en Schmilt conceptos roussonianos como voluntad general y voluntad de todos? El ginebrino "distingue en "El contrato social" estos dos conceptos porque confundirlos sería un gravísimo error. La voluntad de todos es la suma de votos, pero la voluntad general es algo mucho más sutil, $y$ esto es lo que cuenta en democracia.

J.J. Rousseau estaría en esa nómina de filósofos que atraen y a la vez repugnan a los nazis y fascistas en general. Que la sociedad sea un contrato es inadmisible, pues echa por tierra el eslogan "sangre $y$ 
suelo". La sociedad es, pues, algo natural que de ninguna forma puede equipararse a un pacto. Aunque ya hemos tratado este asunto con anterioridad - "el mito nazi" - volveremos sobre ello más adelante, pero ahora volvamos a "la voluntad general".

Leamos a Bernhard Groethuysen ${ }^{21}$ en sus análisis roussonianos: "¿Qué significa esto, como no sea que entre la voluntad general y la voluntad de todos existe una diferencia de principio? la voluntad de todos "que no tiene en cuenta más que el interés privado" está sujeta a error y puede llevar a los Estados a su ruina. Por el contrario, la "voluntad general es siempre recta y tiende siempre a la utilidad pública. Existe por el mero hecho de la asociación, es en cierto modo un "a priori", las fluctuaciones de la voluntad de todos no podrían alterarla."

Más adelante, Groethuysen nos lo aclara algo más. "Si todos los ciudadanos que componen una sociedad son malos ciudadanos, por más que se los consulte, ninguno expresará la voluntad general; si al contrario todos son buenos ciudadanos, bastará consultar a uno sólo, a cualquiera para conocer la voluntad general."

Más aún. "Entonces el verdadero problema en política sería encontrar, para hacer las leyes, un hombre o grupo de hombres cuya voluntad estuviera necesariamente de acuerdo con la voluntad general - que fueran capaces de traducir con decisión la voluntad general en actos legislativos."

$Y$ para concluir: "El verdadero patriota no se parece en nada a ese socio que más preocupado por el bien privado que por el bien público, se vale de su aportación de fondos para reclamar derechos particulares. (...) No confundamos el ideal democrático con una especia de optimismo de la pluralidad, no lo reduzcamos a un principio numérico. Jamás ha pretendido Rousseau que, de todas formas, bastaba contar los votos para que todo marchara lo mejor posible. La democracia no es un régimen tranquilo."

Si ahora nos atenemos a lo aquí expuesto, ipodría dudarse que el régimen nazi fue democrático? Pero no sólo esto, sino que habría que admitir que ha sido el único régimen democrático, y ello por una razón: porque en ningún lugar se ha manifestado la voluntad general como en él. ¿Para qué partidos políticos que sólo persiguen intereses privados, como decía Schmitt? ¿Para qué un parlamento que consume tiempo y recursos en discutir sin tomar decisiones? ¿Qué son esas libertades burguesas que atomizan al individuo alejándolo de la comunidad? ¿Cómo puede haber lucha de clases en un pueblo unido por la sangre? Alemania e Italia son dos regímenes democráticos cuyos ciudadanos están espiritualmente representados $-y$ ésta es la verdadera representación, según Schmitt-por dos líderes que encarnan la voluntad general. 
Entender esto es de vital importancia porque la demonización o satanización del fascismo impide comprenderlo desde dentro, perdiendo de vista que si hubiese sido una cosmovisión torpe o simplemente brutal, jamás hubiese arrastrado a tantos seres humanos. Por esto también los signos de interrogación del título del epígrafe.

\section{Propaganda nazi}

omencemos con unas palabras de Goebbels: "Con una repetición suficiente y la comprensión psicológica de las personas implicadas, no sería imposible demostrar que de hecho un cuadrado es un círculo. Después de todo, ¿qué son un cuadrado y un círculo? Son meras palabras, pueden moldearse hasta disfrazar las ideas."

Uno de los autores que mejor comprendieron el lenguaje totalitario es L. Winkcler ${ }^{22}$, veamos qué tiene que decirnos al respecto:

"En el lenguaje totalitario se logra el blindaje de la doctrina contra la realidad por medio de la independización de los medios retóricos, la destrucción de la frase y la repetición de tópicos y consignas autónomas."

Se trata en principio de una ruptura entre el lenguaje y la realidady, sin embargo, cabría hablar no tanto de ruptura sino más bien de apropiación de la realidad por el lenguaje totalitario, de una definición de aquélla por éste, pues si se admite que el totalitarismo es racional a su modo, algo de la realidad debe estar presente en su discurso, de no ser así, éste sería inocuo.

¿Cómo puede calar un lenguaje así en la población? En una obrita corta pero sustancial, Ideas y crencias, Ortega y Gasset ${ }^{23}$ dice que si "tenemos" ideas, en las creencias "estamos", pues no hay vida humana que no esté constituida por algunas creencias básicas. Pero si bien es cierto que en las creencias se está, no lo es menos que también se está en la duda (queremos salir de dudas, decimos), que no es otra cosa que la negación de la estabilidad, la duda, en suma, es estar en lo inestable como tal: es la vida en el instante del terremoto, de un terremoto permanente y definitivo. Para Ortega, las dudas se convierten en grietas que las ideas tratan de llenar, es decir, que salimos de dudas pensando. ¿Qué ocurre en las sociedades en las que cala el lenguaje totalitario? Que no dudan, que desesperan; las antiguas ideas no sirven y las nuevas no están maduras. Es decir que se asientan en la nada. $\mathrm{Y}$ ¿no es esto el nihilismo? El vacío 
es total. Pues bien justo en esta situación el discurso totalitario entra en escena con fuerza salvadora, revitalizante y tonificante, afirmando con rotundidad sus creencias. i Se podría decir que viene a llenar un vacío de realidad? Sí, pero a un coste inmenso, porque crea una realidad falsa. Veámoslo.

L. Winckler afirma que "el lenguaje fascista destruye la realidad por medio de una estricta cuantificación", pero ¿no es más bien lo contrario? Lo que ocurre, como decía, es que crea una falsa realidad, porque la simplifica y la deforma. Los contenidos repetitivos $y$ simples de la propaganda no hacen sino afianzar, fortalecer y ratificar los ya recibidos en una "educación" de corte conductista -recuérdese el cuento "La seta venenosa"24 que oían los niños desde su más tierna infancia. Si ya en la obra de C. Schmilt leemos que la política se construye en la diferencia amigoenemigo, no podemos sorprendernos ya de nada. Una sociedad que se constituye sobre la base de una racionalidad meramente instrumental, de ahí la cuantificación que mencionaba Winckler, se vuelve adiafórica, indiferente desde el punto de vista moral, pues la razón instrumental, tal y como la entiende Horkheimer ${ }^{25}$, sólo entiende de medios para conseguir fines, fines que ella es incapaz de proponer.

"Como los fines han dejado de ser determinados a la luz de la razón, tampoco resulta posible decir que un sistema económico o político, por cruel y despótico que sea, es menos racional que otro. De acuerdo con la razón formalizada, el despotismo, la crueldad y la opresión no son en si mismos malos, ninguna instancia racional aprobaría un juicio contra la dictadura de tener los portavoces alguna posibilidad de aprovecharse de él. Modos de expresión como "la dignidad del hombre", o implican un avance dialéctico con el que se preserva y transciende la idea del derecho divino, o se convierten en cansadas consignas, cuya vaciedad sale a la luz tan pronto como alguien intenta investigar su significado específico."

En medio de esta brutal simplificación de la realidad y por lo tanto de la vida, sólo pueden emerger "individuos que ya no son capaces de otra cosa que de esperar en espectante silencio la voz que les anuncie lo que deben hacer", como afirma Águila Tejerina $^{26}$. La violencia, entonces, antes de descargarse en el enemigo, se concentra en los futuros victimarios que al quedar paralizados 
moralmente, han perdido toda su capacidad crítica, de análisis, en resumen, se han quedado sin resortes judicativos. Es aquí cuando de nuevo surge la "divinidad" del jefe, del líder, del mesías.
Formalicemos lo dicho hasta aquí. Hemos comprobado que no hay más lenguaje que el propagandístico, pero, ¿cómo definir la propaganda? No es fácil, así que recurriremos a Emma Rodero Antón:

"Se entiende por propaganda la acción sistemática reiterada, ejercida por medios orales escritos o icónicos, sobre la opinión pública, con una finalidad persuasiva, principalmente mediante la sugestión y técnicas sicológicas similares, para imbuir una ideología o doctrina, o incitar a la acción mediante la canalización de actitudes $u$ opiniones, al presentarse la realidad tergiversada, seleccionada e interpretada con un reduccionismo valorativo y gran carga emocional. La propaganda se mueve en una estructura sociocultural determinada, $\sin$ la cual no pueden comprenderse sus repercusiones sicológicas y culturales."

Nadie como los nazis supieron aprovechar los medios que tenían a su disposición para propagar sus mensajes. Si Mussolini prefirió la prensa, Hitler, la propaganda oral e icónica. Y, ¿cuáles son los principios de la propaganda política? Recurramos esta vez a J. M. Domenach ${ }^{27}$ por la exhaustividad:

I. Ley de simplicidad. Es decir carencia por completo de io que en Teoría de la comunicación, llamaríamos "ruido". Además, brevedad y claridad.

2. Ley de la espoleta Se ataca al intelecto por la parte más débil. Debe ser inesperado. El mensaje, de gran carga emocional, se dirige a la parte más vulnerable del individuo.
3. Ley de simpatía Las opiniones y los argumentos del adversario no se discuten, se combaten con provocaciones dirigidas a los sentimientos.

4. Ley de la sorpresa. La mentira más eficaz es una media verdad.

5. Ley de la repetición. "Una mentira repetida mil veces, se convierte en una verdad", Goebbels.

\section{Ley de saturación y desgaste.}

7. Ley de la síntesis. La síntesis es superior al análisis, pues la intuición es superior a la razón.

8. Ley de la dosificación. La presencia y la imagen deben ser constantes en los medios.

9. Ley de orquestación. Todos los medios a la vez. 
Pasemos a las técnicas:

1. Empleo de estereotipos, es decir, poner etiquetas a los seres humanos. Este punto es fundamental, sólo se puede matar con facilidad e impunidad después de quitarle a la víctima su lado humano, así sólo se matan animales.

2. Sustitución de nombres por otros con connotaciones emocionales.

3. Empleo de eslóganes.
4. Selección de determinados hechos para su posterior tergiversación.

5. Señalamiento del enemigo. En este caso, el pueblo judío.

6. La alusión a la autoridad.

En 1936, Hitler afirmaba en el Congreso de Nuremberg: "La propaganda nos ha llevado al poder, nos ha permitido conservarlo; también la propaganda nos concederá la posibilidad de conquistar el mundo."

\section{Estética nazi}

- 19 de julio de 1937, Hitler - pronunció un discurso en la inauguración de la Primera Gran Exposición del Arte Alemán ${ }^{28}$. Se trata de un larguísimo discurso en el que,aparte de dejar claro qué debe ser el arte alemán, aprovecha para arremeter contra los judíos como causantes de la desmoralización y degradación de Alema- nia. Acusa a los judíos primeramente de haber tomado posesión de los instrumentos e instituciones que crean y mueven la opinión pública, de modo que dejaron inseguros $y$ temerosos a aquellos que se interesaban por cuestiones artísticas. El gran pecado de los judíos era proclamar que el arte era internacional.

"Hasta la ascensión del poder del Nacionalsocialismo existía en Alemania un arte considerado "moderno" o, más bien, como propiamente revela la esencia de este término, un arte cada año. Pero la Alemania nacionalsocialista exige un arte nuevamente alemán, y ese debe ser y será, como todos los valores creativos de un pueblo, un arte eterno. Si en vez de eso se revelase falto de tal valor eterno para nuestro pueblo, ya hoy mismo resultaría carente de un valor superior." 
Más adelante afirma que si el Reich es eterno, el arte alemán también lo será.

"Por consiguiente el arte de este nuevo Reich no será valorado en referencia a criterios de viejo o moderno, sino que deberá, como arte alemán, adquirir la propia inmortalidad ante nuestra historia. Porque el arte no es una moda. Igual que mudan poco la esencia y la sangre de nuestro pueblo, en la misma medida el arte debe abandonar el carácter de la caducidad, para resultar en cambio, en sus mejores creaciones, la expresión viva y digna del ritmo vital de nuestro pueblo. Nada tienen que ver con nuestro pueblo el cubismo, el dadaismo, el futurismo, el impresionismo, etc.."

¿Por qué no tienen cabida esas corrientes? "'Obras de arte' que no logran ser comprendidas por sí mismas, sino que exigen antes que nada complicadas instrucciones al uso - a fin de justificar su propia existencia-, con el objetivo de engañar a la persona timorata que supinamente acoge una vacuidad tan insulsa como impúdica, ino encontrarán más, de ahora en adelante, el camino del pueblo alemán!"

$Y$ es que la nueva época considera la creación de un nuevo tipo de hombre. ¿No advertía líneas arriba Hannah Arendt que lo que se buscaba era transformar la naturaleza humana? "Asistimos al nacimiento de un tipo humano admirablemente bello que tras las más altas obras de trabajo celebra la máxima antigua: iáspera semana, pero fiesta gozosa! (...) Este tipo humano, queridos balbuceadores prehistóricos del arte, representa el tipo de la nueva época. $Y$ vosotros, ¿qué producís? ¿Lisiados deformes e idiotas, mujeres que sólo suscitan horror, hombres más seme- jantes a las bestias que a los hombres, niños que, si viviesen en el modo en el que han sido figurados, se creerían simplemente una maldición de Dios!"

Estamos ante lo que se llamó en su día "arte degenerado".

El término "degeneración" se puso de moda en Viena a finales del siglo XIX y su popularidad obedecía al éxito que había alcanzado la teoría de la evolución de Darwin. Más tarde se lo asoció con el parasistismo y luego pasó al campo de la cultura. Max Nordau, médico y escritor sionista, entendía que el arte debe ser sano y constructivo, y relaciona lo degenerado, entendido en términos de regresión, con lo infantil, la pornografía y lo patológico, introduciendo el componente racial al atribuir esta clase de arte, por ejemplo, al supuesto primitivismo de los "hombres amarillos" del Este asiático. El término, que cambió de rumbo, no tardaría en ser aplicado a los judíos en los círculos reaccionarios de Viena. 
-5 Es fácil, pues, comprender los furibundos ataques de Hitler al arte moderno, porque si pensamos, como Lévinas, en el biologismo nazi, el arte se había deshumanizado, como afirmaba Ortega. ${ }^{29}$

El ensayista y filósofo madrileño asegura que el arte nuevo tiene siempre a la masa en contra suyo, porque no es popular o, mejor dicho, por ser antipopular. Divide al público en una minoría que lo disfruta y lo saborea, y una inmensa mayoría que simplemente, no lo entiende: "Mas cuando el disgusto que la obra causa nace de que no se la ha entendido, queda el hombre como humillado, con una oscura conciencia de su inferioridad que necesita compensar mediante la indignada afirmación de sí mismo frente a la obra."

Lo que sucede es que el arte nuevo presenta resortes no humanos, no es para todos. El arte debe mostrar pasiones y figuras humanas, y el público lo aceptará en tanto estos contenidos no sean vulnerados. Pero cabe una tendencia a la purificación del arte y "esta tendencia llevará a una eliminación progresiva de los elementos humanos, demasiado humanos, que dominaban la producción romántica y naturalista. Y en este proceso se llegará a un punto en el que el contenido humano de la obra sea tan escaso que casi ni se le vea."

Las características que hacen de este arte "irritable" son su deshumanización; evita las formas vivas; el arte es arte; el arte es un juego; es irónico; presenta una escrupulosa realización; y sobre todo es intranscen- dente. Si recordamos las palabras de Hitler, entenderemos su ira ante el arte moderno. "Lejos de ir el pintor más o menos torpemente hacia la realidad, se ve que ha ido contra ella. Se ha propuesto denodadamente deformarla, romper su aspecto humano, deshumanizarla.(...) Con las cosas representadas en el cuadro es imposible la convivencia; al extirparles su aspecto de realidad vivida, el pintor ha cortado el puente $y$ quemado las naves que podían transportarnos a nuestro mundo habitual."

Pero es que el arte al ser una de las actividades más libres es el primero o unos de los primeros campos de la cultura en sufrir cualquier cambio de sensibilidad. ¿Qué ocurre si el pintor, en vez de pintar una realidad, pintase una idea, un esquema de ésta? Que estaríamos ante un cuadro, o sea, una irrealidad.

Las obras degeneradas de la Exposición del 37 fueron expuestas siguiendo los mismos procedimientos de los dadaístas, cuadros mal colgados, a veces sin marco, otros acompañados de mensajes provocativos... Asistieron más de dos millones de personas. Conscientes de su valor económico, algunas obras fueron subastadas y vendidas y así las arcas del Reich se incrementaron en quinientos mil francos suizos. El resto de las obras fue a las llamas.

\section{Para no terminar}

El nueve de septiembre de 1973, día domingo, Augusto Pinochet acudió por la noche a la casa 
de Salvador Allende acompañado por otro general de apellido Urbina, ya que el Presidente de la República quería discutir con ellos un grave asunto. La situación chilena estaba muy deteriorada y el presidente Allende quería convocar un referéndum para saber si contaba o no con la confianza del pueblo chileno. Allende les informó de que el aviso a la nación lo daría el lunes $10, y$ en ese momento Pinochet le sugirió que lo pospusiera al miércoles 12 , ya que quería él personalmente notificarlo al ejército para ver las reacciones. Allende consintió sin saber que el golpe ya estaba pensado para el martes 11 .

¿Cuántas vejaciones se cometieron desde entonces? Como decía, han pasado pocos días de la muerte del dictador y ya se empiezan a escuchar voces que tratan de maquillar lo que fue un genocidio. Un analista estadounidense, aunque de origen latino, afirmaba en CNN que la política económica que se puso en marcha tras el golpe era tan impopular como necesaria, y que, gracias a ella, hoy los chilenos disfrutan del mejor nivel de vida de Latinoamérica. Claro, reconocía que dicha política era imposible implantarla con un gobierno democrático, sólo un gobierno como aquél podía lograrlo. No habló ni de golpe de estado, ni de dictadura, ni de torturas, ni de muertes, ni de desapariciones, ni de ausencia de libertades... nada. ¿Para qué, o por qué, lo iba a hacer? Se refirió tibiamente a la dureza de aquellos años, pero nada más. $Y$ es que el fin sigue justificando los medios. Porque que nadie lo dude, se hizo lo que se hizo por el bien de Chile. Pero, zquién es Chile sino los chilenos? ¡Y es precisamente a éstos a quienes se mataba!

Se quiera o no, seguimos pensando con unas categorías simplemente mortíferas, en este caso es la idea de PROCRESO, la que vuelve por enésima vez a justificarlo todo. La misma categoría que escondida al principio mostró lo que es capaz de generar. ¿No hicieron lo que hicieron los nazis por Alemania, o los fascistas por Italia? La categoría es perversa porque no recicla los desechos del matadero de la historia que van quedando en los márgenes, en la cuneta.

Asociamos PROCRESO CON CULTURA, sin darnos cuenta de que, tal y como repite Benjamin, no hay documento de cultura que no sea a la vez de barbarie. Esa próspera economía chilena que disfrutan los vivos, como no podía ser menos, esconde los rostros de todos aquéllos que perdieron su vida y con ello sus sueños e ilusiones, aquéllos que están esperando ser redimidos, aquéllos que esperan justicia porque si no la hay para ellos no la habrá para nadie.

¿Qué habría ocurrido si la razón judía, de presencia importantísima en Occidente, hubiese guiado nuestros pasos? ¿Dónde estaríamos hoy si nos hubiésemos guiado no por la razón instrumental sino por una razón compasiva? 
Notas

H. Arendr, Los origenes del totalitarismo, Pg. 533, Taurus.

J. P. Faye, Los lenguajes totalitarios, Pg. 55, Taurus.

C. Schmitt, Teoria de la Constitución, Alianza.

- B. Mussolini, El Estado corporativo, pgs. 33-34, USI.

3 I. Berlin, Dos conceptos de libertad, Pgs. 47 y 60, Alianza.

b $\quad$ B. Mussolini, Ibid.

' C. Maffesoli, La violencia totalitaria, Pg. 223, Herder.

- E. Jiménez Caballero, “Genio de España", pg. 276, Gaceta literaria.

- Renzo de Felice, El fascismo, sus interpretaciones, Paidós.

10 Umberto Eco, Totalitarismo difuso y fascismo etemo, Pgs. 46-47, Lumen.

$"$ T. Carlyle, Los heroes, Iberia.

12 J. N. Figgis, El derecho divino de los reyes, FCE.

13 Mitos y símbolos del nociomo, Acantibdo.

14 M. Weber, Economia y sociedad, FCE.

is Recuérdese a Benjamin.

16 H. Arendr, Op. cit.
17 Recuérdese a Benjamin.

18 P. Bachrach, Crítica de La teoría elitista de la democracia, Amorrortu.

19 G. Mosca, La clase política, FCE.

20 C. Schmitt, Sobre el parlamentarismo, Tecnos.

21 B. Groethuyssen, J.J. Rousseau, FCE.

22 L. Winckler, La función social del lenguaje fascista, Ariel.

23 Ortega y Gasset, Ideas y creencias, Espasa Calpe.

24 Se trataba de un cuento muy popular que escuchaban los niños en su casa y en las escuelas. Una madre le enseña a su hijo un día de campo a recoger las setas. Le señala cuáles son las comestibles $\mathrm{y}$ las venenosas. A continuación le señala un tipo de setas de un aspecto increlble por su belleza. Éstas son las más peligrosas, son mortales: son los judíos.

25 M. Horkheimer, Cretica de la razón instrumental, pg. 67, Trotta.

26 Rafael del Águila, Ideologia y fascismo, CEC.

2) J. M. Domenach, La propaganda polírica, EUDEBA.

20 Se puede hallar en Internet.

29 Ortega y Gasset, La deshumanizacion del arte, Espasa Calpe. 